\title{
Genetic polymorphisms associated with the inflammatory response in bacterial meningitis
}

\author{
Fabrícia Lima Fontes ${ }^{1}$, Luíza Ferreira de Araújo ${ }^{1}$, Leonam Gomes Coutinho ${ }^{1}$, Stephen L. Leib ${ }^{2}$ and \\ Lucymara Fassarella Agnez-Lima ${ }^{1,3^{*}}$
}

\begin{abstract}
Background: Bacterial meningitis (BM) is an infectious disease that results in high mortality and morbidity. Despite efficacious antibiotic therapy, neurological sequelae are often observed in patients after disease. Currently, the main challenge in BM treatment is to develop adjuvant therapies that reduce the occurrence of sequelae. In recent papers published by our group, we described the associations between the single nucleotide polymorphisms (SNPs) AADAT +401C > T, APEX1 Asn148Glu, OGG1 Ser326Cys and PARP1 Val762Ala and BM. In this study, we analyzed the associations between the SNPs TNF -308G > A, TNF -857C > T, IL-8 -251A > T and BM and investigated gene-gene interactions, including the SNPs that we published previously.

Methods: The study was conducted with 54 BM patients and 110 healthy volunteers (as the control group). The genotypes were investigated via primer-introduced restriction analysis-polymerase chain reaction (PIRA-PCR) or polymerase chain reaction-based restriction fragment length polymorphism (PCR-RFLP) analysis. Allelic and genotypic frequencies were also associated with cytokine and chemokine levels, as measured with the X-MAP method, and cell counts. We analyzed gene-gene interactions among SNPs using the generalized multifactor dimensionality reduction (GMDR) method.
\end{abstract}

Results: We did not find significant association between the SNPS TNF -857C > T and IL-8 -251A > T and the disease. However, a higher frequency of the variant allele TNF -308A was observed in the control group, associated with changes in cytokine levels compared to individuals with wild type genotypes, suggesting a possible protective role. In addition, combined inter-gene interaction analysis indicated a significant association between certain genotypes and BM, mainly involving the alleles APEX1 148Glu, IL8 -251 T and AADAT +401 T. These genotypic combinations were shown to affect cyto/chemokine levels and cell counts in CSF samples from BM patients.

Conclusions: In conclusion, this study revealed a significant association between genetic variability and altered inflammatory responses, involving important pathways that are activated during BM. This knowledge may be useful for a better understanding of BM pathogenesis and the development of new therapeutic approaches.

\section{Background}

Despite immunization programs and effective antimicrobial therapies against bacterial meningitis $(\mathrm{BM})$, the incidences of mortality and neurological sequelae caused by this disease remain high [1]. A complex series of events involving host cytokines, chemokines, proteolytic enzymes and oxidizing agents appear to be responsible for

\footnotetext{
*Correspondence: Ifagnez@ufrnet.br

'Departamento de Biologia Celular e Genética, Universidade Federal do Rio Grande do Norte, UFRN, Natal, Brazil

${ }^{3}$ Departamento de Biologia Celular e Genética, Centro de Biociências UFRN, Campus Universitário, Lagoa Nova, Natal, RN 59078-970, Brazil Full list of author information is available at the end of the article
}

the occurrence of brain damage during BM. This response depends not only on the type and intensity of the stimulation but also on host genetic factors, such as genetic polymorphisms located in coding or regulatory regions of key genes [2-4].

BM is characterized by an acute inflammatory response that is initiated by the presence of bacterial pathogens in the central nervous system (CNS). The disease begins with nasopharyngeal colonization by the pathogen and subsequent invasion of the bloodstream. During this phase, BM can be avoided with efficient innate and acquired immune responses [2, 4]. 
Several bacterial species that are pathogenic to humans have the potential to cause meningitis, but a relatively small number of pathogens, as Haemophilus influenzae type $b$ [Hib], Streptococcus pneumoniae and Neisseria meningitides, are responsible for the majority of acute BM cases $[5,6]$. These primary pathogens utilize distinct but overlapping sets of Toll-like receptors (TLRs) to trigger the inflammatory response, inducing NF- $\mathrm{kB}$ activation in a MyD88-dependent pathway [7-9]. Corroborating these data, in a recent study published by our group, we observed a similar profile of cytokine expression during pneumococcal and meningococcal meningitis [10]. Tumor necrosis factor (TNF- $\alpha$ ), IL-1 $\beta$ and IL- 6 are the major early response cytokines that trigger a cascade of inflammatory mediators, including other cytokines, chemotactic cytokines (chemokines) such as CXCL8/ IL-8, MIP-1 $\alpha / C C L 3, \quad$ MIP-1 $\beta / C C L 4, \quad$ MCP-1/CCL2, prostaglandins, matrix metalloproteinases (MMPs), reactive oxygen species (ROS) and reactive nitrogen intermediates (RNI) [2, 9, 11].

In previous studies, we described the associations between $\mathrm{BM}$ and the single nucleotide polymorphisms (SNPs) $A A D A T+401 \mathrm{C}>\mathrm{T} \quad(\mathrm{rs} 1480544)$ [12], APEX1 Asn148Glu (rs1130409), OGG1 Ser326Cys (rs1052133) and PARP1 Val762Ala (rs1136410) [13]. The AADAT gene encodes the enzyme kynurenine aminotransferase II, which is involved in the kynurenine (KYN) pathway, the major route for tryptophan degradation in the brain. Alterations in this pathway are associated with several diseases that compromise the CNS [14]. APEX1, OGG1 and PARP1 encode DNA repair enzymes involved in the base excision repair (BER) pathway, one of the most important pathways for the repair of oxidized DNA damage in neurons [15].

In this study, we analyzed the associations between the SNPs TNF -308G > A (rs1800629), TNF $-857 \mathrm{C}>\mathrm{T}$ (rs1799724), and IL8 -251A > T (rs4073) and BM. In addition, we also investigated gene-gene interactions, including the SNPs previously investigated by our group $[12,13]$. The SNPs TNF -308G $>\mathrm{A}$ and TNF - 857C $>\mathrm{T}$ are localized in the regulatory region of the TNF promoter and were described to be involved in increased transcriptional activity of the TNF gene [16-18]. CXCL8/IL-8 is involved in the chemotactic activity of polymorphonuclear and mononuclear cells. The genetic polymorphisms IL8 -251A > T causes decreased expression of this chemokine [19-21].

Although several molecular markers have become areas of focus for research, few studies have considered the interplay between markers. In this study, we investigated genetic association data from a model for susceptibility to BM that integrated important routes that are activated during the disease. Our findings demonstrated a higher frequency of variant allele TNF -308A in the control group, suggesting a possible protective role against disease, and genetic combinations, primarily involving the alleles TNF -308G, APEX1 148Glu, IL8 $-251 \mathrm{~T}$ and $A A D A T+401 \mathrm{~T}$, that were associated with the occurrence of BM.

\section{Methods}

\section{Ethics statement}

This work was approved by the Brazilian Ethics Committee (CONEP, CAAE 0052.1.051.000-05). All subjects signed the informed consent agreeing to participate in this research. In the case of minors/child participants involved in this study, we obtained informed written consent from the legal guardians.

\section{Study population and samples}

The study was conducted with a group of 54 patients (35 men and 19 women), 21 individuals were 18 years or younger, 25 aged from 18 to 60 years, 4 individuals aged over 60 years, and 4 with unknown age. The patients were admitted in the Hospital Giselda Trigueiro (HGT), Natal$\mathrm{RN}$, Brazil, which is a reference hospital for infectious diseases in the state. BM diagnosis was based on the hospital routine, which includes: (1) positive CSF bacterial culture, (2) detection of the pathogen in the CSF by Gram staining plus clinical signs (acute onset, fever, meningeal irritation) and/or (3) positive blood culture or Gram stain in the presence of clinical signs of meningitis, (4) positive bacterial antigen detection in the CSF or blood using the latex agglutination test, with clinical signs of meningitis, (5) CSF parameters including increased protein content $(>40 \mathrm{mg} / \mathrm{dL})$, reduced glucose levels $(<40 \mathrm{mg} / \mathrm{dL})$ and the presence of CSF pleocytosis ( $\geq 500$ cells $/ \mathrm{mm} 3$ ), with predominantly polymorphonuclear granulocytes (PMN), and (6) symptoms such as high fever, chills, severe headache, nausea and vomiting, and the Kernig and Brudzinski signs of meningo-radicular syndrome. However, some patients with clinical manifestations of bacterial meningitis were on antibiotic treatment prior to definitive diagnosis, so it was not possible to define accurately the etiologic agent. These patients were used only for genotypes analysis and excluded from the inflammatory markers analysis. Moreover, patients undergoing chronic treatment with antiinflammatory or with other diseases (such as AIDS) that affect the immune and inflammatory responses (e.g., cytokine expression) were excluded from the study. Healthy volunteers and patients attended at the HGT, who had a negative diagnosis for infectious disease, were included in the study as part of the control group, a total of 110 samples (53 men and 57 women), 10 individuals were 18 years or younger, 99 individuals aged from 18 to 60 years and 1 individuals aged over 60 years. These patients were used as controls given that no infection was confirmed and all parameters for diagnosis were normal. 
In healthy volunteers, CSF samples were not collected, as lumbar puncture is a very invasive method, but a questionnaire evaluating the history of infectious and inflammatory diseases was administered to the healthy volunteers. In addition, blood samples were submitted to obtain white blood cell counts (WBC) and differentials, cytokines and chemokines were analyzed, and it was determined whether the individual had a fever at the time of collection of the biological sample. In relation to BM, 54 patients had a positive diagnosis: 17 were diagnosed with S. pneumonia; 7 with N. meningitides; 6 with other pathogens; and 24 without a specified etiology. CSF biochemical parameters of each causative agent are shown in Table 1 (more detail can be found in [10] and [22]).

\section{Sample collection and processing}

Blood samples were collected and processed by centrifugation at $2,880 \mathrm{~g}$ and $4{ }^{\circ} \mathrm{C}$ for $3 \mathrm{~min}$ to separate the plasma. Genomic DNA extraction was performed using the salting out procedure following the protocol described by Miller et al. [23]. Samples of CSF were collected upon lumbar puncture (LP) and centrifuged at $720 \mathrm{~g}$ for $5 \mathrm{~min}$. Supernatants were frozen and stored at $-80{ }^{\circ} \mathrm{C}$ before any further procedure. Blood samples were obtained from all patients and volunteers. However, given that LP is a very invasive procedure, CSF samples were obtained only from patients undergoing procedures for the diagnosis of meningitis. Patients who had a positive diagnosis were included in the BM group.

\section{Genotypic analysis}

The SNPs investigated in this study are detailed in Table 2. The primer sequences for TNF -308G > A, TNF - 857C > $\mathrm{T}$, and $I L 8-251 \mathrm{~A}>\mathrm{T}$ have been previously described [2426]. Primer-introduced restriction analysis-polymerase chain reaction (PIRA-PCR) was carried out to identify the SNP TNF -308G > A, containing a single-base mismatch leading to the amplification of $\mathrm{PCR}$ products containing a restriction site. For all SNPs, genotyping was performed following the digestion of the amplified fragments with appropriate restriction endonucleases using the methodology for restriction fragment length polymorphism (PCRRFLP) (Table 3). PCR was carried out using $100 \mathrm{ng}$ of genomic DNA in a $25-\mu \mathrm{l}$ volume reaction containing $1 \mathrm{X}$ specific buffer, $10 \mathrm{pM}$ of each primer, $2.0 \mathrm{mM} \mathrm{MgCl} 2,0.3$
mMol of each dNTP, and $3.6 \mathrm{U}$ of Taq polymerase. The PCR conditions were as follows: initial denaturation at $94{ }^{\circ} \mathrm{C}$ for $5 \mathrm{~min}$, followed by 35 cycles of $45 \mathrm{~s}$ at $94{ }^{\circ} \mathrm{C}$ for denaturation and annealing for $45 \mathrm{~s}$ (temperatures given in Table 3), elongation at $72{ }^{\circ} \mathrm{C}$ for $1 \mathrm{~min}$, and a final extension step at $72{ }^{\circ} \mathrm{C}$ for $5 \mathrm{~min}$. PCR products were run on $2 \%$ agarose gels and visualized with ethidium bromide. The digestion of PCR products was performed following the instructions of the manufacturers of the restriction enzymes. The digestion products were analyzed on an $8 \%$ polyacrylamide gel and were revealed with silver staining according to the protocol described by Sanguinetti et al. [27]. Quality control was carried out with $20 \%$ repetition of the entire sample for each SNP to evaluate data reproducibility.

\section{Cytokine multiplex measurements in CSF and plasma}

Proinflammatory cytokine and chemokine levels in the CSF and plasma were measured during the acute phase of disease and before the start of treatment with antibiotics. Analysis was performed with microsphere-based multiplex assays (xMAP Luminex technology) using the Bio-Plex 200 suspension array system (Bio-Rad, Hercules, CA, USA). A human cytokine Lincoplex Kit (HCYTO$60 \mathrm{k}$, Millipore, Billerica, Ma, USA) was used to analyze a set of 12 cytokines and chemokines (TNF- $\alpha$, IL-6, IL-1 $\beta$, INF- $\gamma$, IL-2, IL-10, IL-1RA, MIP- $1 \alpha / C C L 3$, MIP-1 $\beta / C C L 4$, MCP-1/CCL2, G-CSF and IL-8/CXCL8). The samples were processed and measured according to the manufacturer's instructions, as described previously $[10,12,13]$. Cyto/chemokine expression was measured in duplicate, and the inflammatory modulators levels were analyzed in relation to a parametric logistic curve using Bio-Plex manager 4.01 software and expressed as $\mathrm{pg} / \mathrm{ml}$. Due to the low quantities of biological material, evaluation of all patients was not possible.

\section{Statistical analysis}

Allelic and genotypic frequencies were calculated for patient and control subjects via direct gene counting. Hardy-Weinberg equilibrium was evaluated using GENEPOP 4.2 software (http://genepop.curtin.edu.au/). For linkage disequilibrium analysis (LD) of the TNF -308G > A and TNF $-857 \mathrm{C}>\mathrm{T}$ polymorphisms, Haploview software version 4.2 was used as described previous [28].

Table 1 CSF biochemical parameters of BM meningitis etiologies

\begin{tabular}{lllll}
\hline CSF $(\mathrm{n}$ samples) & Age (years) & Cell count $\left(\right.$ cells $\left./ \mathrm{mm}^{3}\right)$ & Protein $(\mathrm{mg} / \mathrm{dL})$ & $\mathrm{Glucose}(\mathrm{mg} / \mathrm{dl})$ \\
\hline S. pneumonia $(17)$ & $27(11 ; 43)$ & $1,960(698 ; 83,730)$ & $198.00(137.50 ; 339,00)$ & $17(4 ; 26.70)$ \\
N. meningitides $(7)$ & $21(6 ; 27)$ & $1,120(3,440 ; 14,400)$ & $177.0(88.00 ; 314.00)$ & $7.3(2 ; 47.90)$ \\
Other pathogens $(6)$ & $7(1 ; 15)$ & $3,083(1,835 ; 5,998)$ & $218.5(174.00 ; 317.80)$ & $4.1(0 ; 29.25)$ \\
Unknown etiology $(24)$ & $22(6 ; 46)$ & $505(159 ; 1490)$ & $78.20(35.00 ; 1350.00)$ & $51,60(45.10 ; 70.00)$ \\
\hline
\end{tabular}

Values are represented as medians $(25 ; 75$ percentiles) 
Table 2 Polymorphisms analyzed in this study

\begin{tabular}{lllll}
\hline Polymorphism & Reference & Chromosome & Functional position & Wild type/rare allele \\
\hline TNF -308G > A & rs1800629 & 6 & promoter region & $\mathrm{G} / \mathrm{A}$ \\
TNF -857C > T & rs1799724 & 6 & promoter region & $\mathrm{C} / \mathrm{T}$ \\
IL8 -251A > T & rs4073 & 4 & promoter region & $\mathrm{A} / \mathrm{T}$ \\
APEX1 Asn148Glu & rs1130409 & 14 & exon & $\mathrm{G} / T$ \\
OGG1 Ser326Cys & rs1052133 & 3 & exon & $\mathrm{C} / \mathrm{G}$ \\
PARP1 Val762Ala & rs1136410 & 1 & exon & $\mathrm{T} / \mathrm{C}$ \\
AADAT +401C > T & rs1480544 & 4 & splice site & $\mathrm{C} / T$ \\
\hline
\end{tabular}

Logistic regression analyses were used to calculate odds ratios (OR), $95 \%$ confidence intervals (CI) and corresponding $P$-values to determine the association between each variant and susceptibility to BM. In this analysis, the effects of age and sex were evaluated. STATA software (version 11.0; Stat Corporation, College Station, Texas, USA) was used to conduct this statistical analysis. The generalized multifactor dimensionality reduction (GMDR) analysis was used to assess gene-gene interactions with GMDR Beta 0.9 software. This method has been shown to be effective for detecting gene-gene interactions in case-control studies with relatively small sample sizes. The best statistical gene-gene interactions model for a given order of interaction was determined by three factors: the cross-validation consistency statistics for the selected SNP combinations, the prediction accuracies and the significance level or $P$-value, for which all possible interactions were tested 10 times in an exhaustive search $[29,30]$. A total of 1,000 permutation tests were performed in each analysis. For statistical analysis, we used the autosomal dominant model ( $\mathrm{Aa}+$ aa vs. AA) wherein the presence of the "a" allele is sufficient to show the phenotype. In addition, differences in levels of inflammatory modulators were analyzed using GraphPad Prism5 software. It was used the nonparametric Mann-Whitney $U$ test, for comparisons between two groups, and Kruskal-Wallys test followed by Dunn's Multiple Comparison post-test. For the correlation analysis, it was used the Spearman test.. Values of $P<0.05$ (two-tailed) were considered statistically significant.

\section{Results}

\section{Genotypic frequency analysis}

The distribution of the genotypic frequencies of the TNF $-308 \mathrm{G}>\mathrm{A}, T N F-857 \mathrm{C}>\mathrm{T}$, and $I L 8-251 \mathrm{~A}>\mathrm{T}$ polymorphisms in BM patients and controls are shown in Table 4. All genotypic distributions were in HardyWeinberg equilibrium (Additional file 1: Table S1). Haplotype analysis indicated a D' value of 0.11 for the TNF polymorphisms $-308 \mathrm{G}>\mathrm{A}$ and $-857 \mathrm{C}>\mathrm{T}$, suggesting that they segregate independently (Additional file 1 : Figure S1). No significant differences between the BM and control groups were found in relation to the SNPs TNF $-857 \mathrm{C}>\mathrm{T}$ and $I L 8-251 \mathrm{~A}>\mathrm{T}$. However, in the multivariate regression model, an association between the SNP TNF $-308 \mathrm{G}>\mathrm{A}$ and a possible protective role against $\mathrm{BM}$ was observed; even after adjustment for age and sex, the comparison remained statistically significant $(P=0.020$ and $P$ adjusted $=0.030)$. Individuals carrying the GA genotype demonstrated a significant reduction for $\mathrm{BM}$ risk compared to those carrying the GG genotype $(\mathrm{OR}=0.292$ and $95 \% \mathrm{CI}=0.12-0.711)$. Individuals carrying the AA genotype had an OR of 0.375 compared with carriers of the GG genotype (95\% CI $=0.041-$ $0.711)$. The frequency of the variant allele was decreased in the BM group (0.08) compared to the control group (0.18). Of a total of 163 individuals genotyped for the SNP TNF -308G > A, $70 \%$ were homozygous for the wild type allele, $26 \%$ were heterozygous, and $4 \%$ were homozygous for the variant allele.

The individual allelic and genotypic frequencies for the SNPs $A A D A T+401 C>\mathrm{T}$, APEX1 Asn148Glu, OGG1

Table 3 PCR conditions for genotyping: primer sequences, annealing temperatures and restrictions enzymes

\begin{tabular}{llll}
\hline SNP & Primer sequence & Annealing temperature & Restriction enzyme \\
\hline TNF -308G $>$ A & F 5'AGGCAATAGGTTTGAGGGCCAT'3 & $55^{\circ} \mathrm{C}$ & Ncol \\
TNF -857C > T & & \\
& R 5'TCCTCCCTGCTCCGATTCCG'3 & $58^{\circ} \mathrm{C}$ & Tail \\
IL8 -251A $>$ T & R 5'CCTCTACATGGCCCTGTCTAC'3 & & Asel \\
& F 5'CCATCATGATAGCATCTGTA'3 & $53^{\circ} \mathrm{C}$ & \\
\hline
\end{tabular}


Table 4 Genotypic frequencies of the SNPs for BM compared with the control group

\begin{tabular}{|c|c|c|c|c|c|c|}
\hline Genotypes and alleles & Control group n (\%) & BM group n (\%) & $P$ for difference & OR (95 \% Cl) & Adjusted $P$ for difference ${ }^{a}$ & Adjusted OR $(95 \% \mathrm{Cl})^{\mathrm{a}}$ \\
\hline TNF -308 & \multicolumn{6}{|c|}{ (controls $=109 ;$ cases $=54)$} \\
\hline GG & $69(63)$ & $46(85)$ & $0.020^{*}$ & 1 & $0.030^{*}$ & 1 \\
\hline GA & $36(33)$ & $7(13)$ & & $0.292(0.12-0.711)$ & & $0.319(0.129-0.790)$ \\
\hline AA & $4(4)$ & $1(2)$ & & $0.375(0.041-0.711)$ & & $0.311(0.033-2.943)$ \\
\hline TNF -857 & \multicolumn{6}{|c|}{$($ controls $=107 ;$ cases $=52)$} \\
\hline $\mathrm{CC}$ & $81(76)$ & $39(75)$ & 0.92 & 1 & 0.92 & 1 \\
\hline CT & $26(24)$ & $13(25)$ & & $1.038(0.482-2.237)$ & & $1.475(0.475-2.290)$ \\
\hline$\pi$ & $0(0)$ & $0(0)$ & & & & \\
\hline IL8 - -251 & \multicolumn{6}{|c|}{ (controls $=106 ;$ cases $=52)$} \\
\hline AA & $31(29)$ & $12(23)$ & 0.62 & 1 & 0.68 & 1 \\
\hline AT & $43(41)$ & $25(48)$ & & $1.502(0.656-3.44)$ & & $1.398(0.596-3.280)$ \\
\hline$\pi$ & $32(30)$ & $15(29)$ & & $1.211(0.490-3.00)$ & & $1.058(0.416-2.690)$ \\
\hline
\end{tabular}

$B M$ bacterial meningitis, $O R$ odds ratio, $C l$ confidence interval. Data analyzed by multivariate logistic regression analyses. ${ }^{*}$ Statistical significance $(P<0.05)$. The reference group in each of the analyses was the most prevalent genotype. ${ }^{\mathrm{a} D a t a}$ adjusted for age and gender

Ser326Cys and PARP1 Val762Ala were previously published [12, 13].

\section{Gene-gene interaction analysis}

To identify possible combinations of genotypes that could affect the occurrence of the disease, we performed an analysis of gene-gene interactions for each polymorphism. According to the GMDR data, four different combination models were obtained, which suggested the best models for the combination of all SNPs that exhibited associations with BM (Table 5). We determined the best interaction models based on a cross-validation of $>7$ of 10 , a prediction accuracy $>55 \%$ and a $P$-value $<0.05$ for each model. The combinations of APEX1 Glu/_, AADAT T/_ $(P=$ 0.0107), IL8 T/_APEX1 Glu/_AADAT T/_ $(P=0.0010)$, IL8 T/_,APEX1 Glu/_, OGG1 Cys/_PARP1 Ala/_, and $A A D A T \mathrm{~T} / \_(P=0.0107)$ were statistically significant, suggesting the variants together may contribute to the occurrence of disease. The combination of the three variant alleles of the DNA repair enzymes was also more frequent in the BM group, although it was not statistically significant $(P=0.0547)$, but the best combination was the two-

Table 5 GMDR results of multi-locus interaction with BM compared with the control group

\begin{tabular}{|c|c|c|c|}
\hline Best model (All susceptibility SNPs) & Testing balanced accuracy & Sign test ( $P$-value) & Cross-validation accuracy \\
\hline$\overline{A A D A T \mathrm{~T} /}$ & 0.6305 & $9(0.0107)^{*}$ & $9 / 10$ \\
\hline APEX1 Glu/_,AADAT T/_ & 0.6359 & $9(0.0107)^{*}$ & $9 / 10$ \\
\hline IL8 T/_APEX1 Glu/_,AADAT T/_ & 0.6586 & $10(0.0010)^{*}$ & $10 / 10$ \\
\hline IL8 T/_APEX1 Glu/_OGG1 Cys/_,AADAT T/_ & 0.5743 & $6(0.3770)$ & $6 / 10$ \\
\hline IL8 T/_APEX1 Glu/_,OGG1 Cys/_PARP1 Ala/_AADAT T/_ & 0.6302 & $9(0.0107)^{*}$ & $10 / 10$ \\
\hline Best model (DNA repair enzymes) & Testing balanced accuracy & Sign test ( $P$-value) & Cross-validation accuracy \\
\hline APEX1 Glu/_ & 0.6605 & $9(0.0107)^{*}$ & $10 / 10$ \\
\hline APEX1 Glu/_, OGG1 Cys/_, & 0.5850 & $9(0.0107)^{*}$ & $8 / 10$ \\
\hline APEX1 Glu/_, OGG1 Cys/_,PARP1 Ala/_, & 0.6510 & $8(0.0547)$ & $10 / 10$ \\
\hline Best model (protection SNPs) & Testing balanced accuracy & Sign test ( $P$-value) & Cross-validation accuracy \\
\hline TNF-308 A/ & 0.5939 & $9(0.0107)^{*}$ & $10 / 10$ \\
\hline TNF-308 A_, TNF-857 T & 0.5758 & $8(0.0547)$ & $10 / 10$ \\
\hline Best model (susceptibility alleles) & Testing balanced accuracy & Sign test ( $P$-value) & Cross-validation accuracy \\
\hline TNF-308 GG, AADAT T/_ & 0.6267 & $8(0.0547)$ & $7 / 10$ \\
\hline TNF-308 GG, AADAT T/_,APEX1 Glu/_IL8 T/_, & 0.6108 & $9(0.0107)^{*}$ & $7 / 10$ \\
\hline TNF-308 GG, AADAT T/_, APEX1 Glu/_, IL8 T/_, OGG1 Cys/_ & 0.5528 & $7(0.1719)$ & $5 / 10$ \\
\hline TNF-308 GG, AADAT T/_,APEX1 Glu/_, IL8 T/_, OGG1 Cys/_,PARP1 Ala/_, & 0.5553 & $7(0.1719)$ & $10 / 10$ \\
\hline
\end{tabular}

${ }^{*}$ Significant $P$-value $(P<0.05)$; $P$-value was based on 1,000 permutations. Dominant inheritance model (Aa + aa vs. AA) 
locus model with APEX1 Glu/_ and OGG1 Cys/_ $(P=$ $0.0107)$. Regarding phenotypes that conferred susceptibility to $\mathrm{BM}$, the best gene-gene interaction model was the wild type genotype of TNF -308G/G with APEX1 Glu/, IL8 - $251 \mathrm{~T} /$ and AADAT +401 T/_ $(P=0.0107)$.

In addition, although isolated effects of the SNP TNF $-857 \mathrm{C}>\mathrm{T}$ were not observed, the combination of both variants of the TNF gene resulted in marginal significance $(P=0.0547)$ in terms of the protection against the disease. Together, the data obtained reveal possible associations between different genes that may interact with each other, leading to the occurrence of BM.

\section{Association of SNPs with immune response markers}

In the analysis of cyto/chemokines in relation to individual genotypes, we observed some significant changes between the BM and control groups for the SNP TNF -308G > A alone. An increase in TNF- $\alpha$ and IL-6 levels was observed in CSF samples from BM patients carrying the polymorphic $T N F-308 \mathrm{~A}$ allele (Fig. 1a), while an increase in TNF- $\alpha$ and MCP-1 was observed in plasma samples from the control group (Fig. 1b). The SNP TNF $-308 \mathrm{G}>\mathrm{A}$ did not exert an effect on other inflammatory modulators (Additional file 1: Figure S2). For the SNPs $T N F-857 \mathrm{C}>\mathrm{T}$ and $I L 8-251 \mathrm{~A}>\mathrm{T}$, no significant difference in the levels of immune markers was observed.

Synergism between the SNPs was also investigated. Patients carrying the combination of APEX1 148Glu/_ plus IL8 - $251 \mathrm{~T} /$ _ exhibited reduced levels $(P<0.05)$ of IL-1 $\beta$ and MIP-1ß/CCL4 (Fig. 2a). The combination of IL8 T/ plus $A P E X 1 \mathrm{Glu} /$ _ plus $A A D A T \mathrm{~T} /$ _ also induced the reduction of cytokines TNF- $\alpha$, MIP- $1 \alpha /$ CCL3, and MIP$1 \beta / C C L 4$ (Fig. $2 b$ ) in CSF samples from BM patients. In presence of the three variant alleles of the DNA repair genes, a decrease $(P<0.05)$ in the levels of TNF- $\alpha$, MIP$1 \alpha /$ CCL3, MIP- $1 \beta / C C L 4$, and G-CSF in the CSF (Fig. 2c) was observed. The other combinations did not demonstrate significant changes in the concentrations of cyto/ chemokines (Additional file 1: Figures S3 and S4).

The relationships between the levels of these inflammatory modulators and cell counts in the CSF of BM patients were also assessed in terms of genotypic combinations. A significant reduction in cell count was observed in patients with the combined genotype APEX1 $148 \mathrm{Glu} /$ _ plus IL8 -251T/_ or APEX1 148Glu/_ plus $A A D A T+401 \mathrm{~T} /$ _ (Figs. 2d and e). Analysis of these combinations demonstrated significant correlations between cell count and IL- $1 \beta$, IL- 6 , TNF- $\alpha$, MIP- $1 \alpha / C C L 3$, MIP$1 \beta /$ CCL4 and G-CSF (Table 6). These data suggest a possible synergism between the polymorphisms, given that an additive effect in terms of reduced levels of inflammatory modulators was observed. Other genotypic combinations did not achieve significance in terms of cell count (Additional file 1: Figure S5).

\section{Discussion}

The genetic characteristics of patients are considered important factors in BM occurrence [2-4]. In a previous
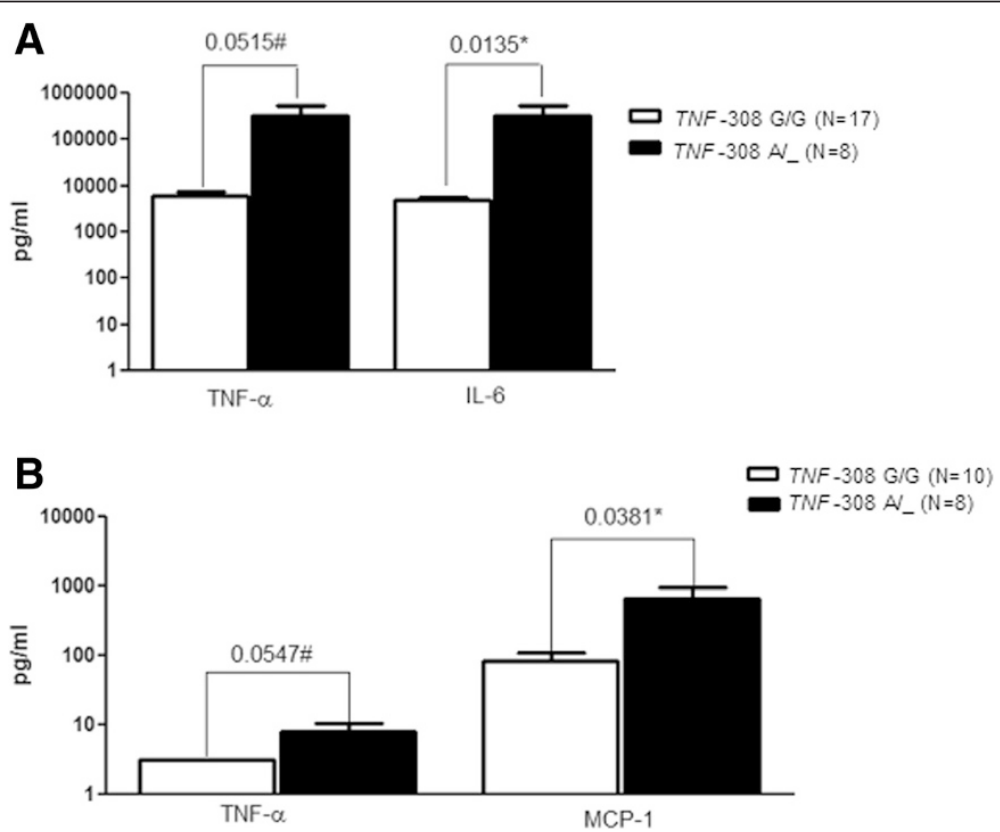

Fig. 1 Cytokine and chemokine concentrations in relation to the genotype for SNP TNF -308G > A. a CSF samples of BM patients. b Plasma samples of controls. Legend: White Bar - cytokine levels for patients with ancestral genotype; Black bar - cytokine levels for patients with at least one polymorphic allele. *Statistical significance $(P<0.05)$; \# borderline values 


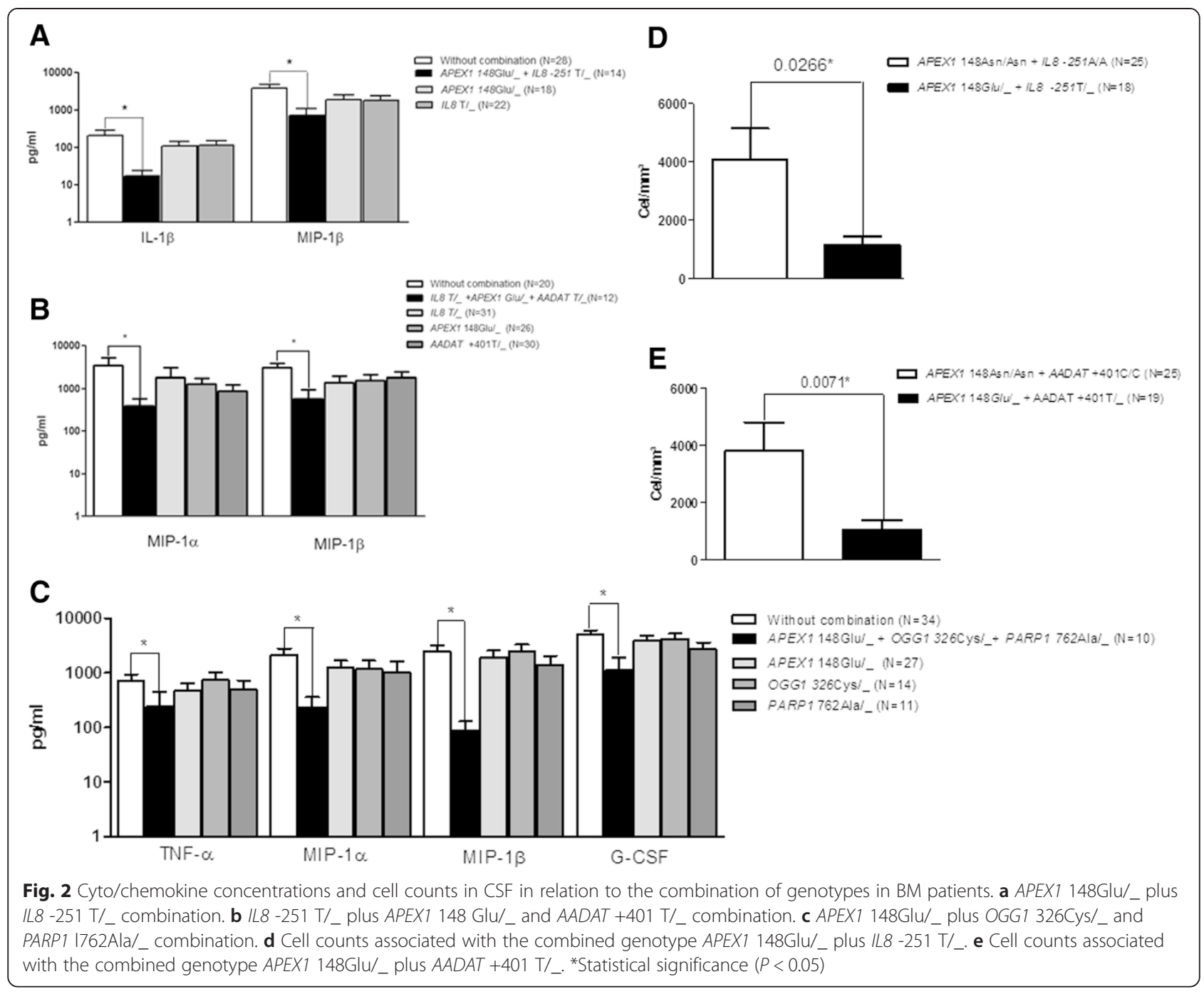

Table 6 Correlation between cell count and cytokine and chemokine levels in CSF from BM patients in terms of genotypic combinations

\begin{tabular}{|c|c|c|c|c|c|c|c|}
\hline \multirow{2}{*}{$\frac{\text { Genotypic combinations }}{\text { APEX1 + } 148 \text { Asn/Asn plus IL8 -251 AA }}$} & \multicolumn{7}{|c|}{ Cytokines and chemokines } \\
\hline & IL-1 $\beta$ & IL-6 & TNF-a & MIP1-a & MIP1- $\beta$ & MCP-1 & G-CSF \\
\hline Spearman $r$ & 0.428 & 0.305 & 0.391 & 0.204 & 0.422 & -0.155 & -0.037 \\
\hline$P$-value & $0.047^{*}$ & 0.168 & 0.072 & 0.363 & $0.050^{*}$ & 0.490 & 0.870 \\
\hline APEX1+48Glu/_plus IL8-251 T/_ & $\mathbb{I L}-1 \beta$ & IL-6 & TNF-a & MIP1-a & MIP1- $\beta$ & MCP-1 & G-CSF \\
\hline Spearman $r$ & 0.830 & 0.547 & 0.781 & 0.735 & 0.791 & 0.346 & 0.788 \\
\hline$P$-value & $<0.001^{*}$ & $0.019^{*}$ & $0.0013^{*}$ & $<0.001^{*}$ & $<0.001^{*}$ & 0.159 & $<0.001^{*}$ \\
\hline APEX1 + 148 Asn/Asn plus AADAT+ 401 CC & $\| \mathrm{L}-1 \beta$ & IL-6 & TNF- $a$ & MIP1-a & MIP1- $\beta$ & MCP-1 & G-CSF \\
\hline Spearman $r$ & 0.111 & 0.506 & 0.311 & -0.100 & 0.032 & -0.007 & -0.104 \\
\hline$P$-value & 0.673 & $0.038^{*}$ & 0.224 & 0.701 & 0.903 & 0.978 & 0.691 \\
\hline APEX1 + $148 \mathrm{Glu} /$ _ plus AADAT +401 T/_ & $\mathbb{I L}-1 \beta$ & IL-6 & TNF-a & MIP1-a & MIP1- $\beta$ & MCP-1 & G-CSF \\
\hline Spearman $r$ & 0.783 & 0.623 & 0.579 & 0.507 & 0.645 & 0.060 & 0.625 \\
\hline$P$-value & $<0.001^{*}$ & $0.007^{*}$ & $0.005^{*}$ & $0.012^{*}$ & $0.005^{*}$ & 0.818 & $0.007^{*}$ \\
\hline
\end{tabular}

"Significant $P$-value $(P<0.05)$. Correlation analysis was performed using a two-tailed Spearman test (cell count vs. cytokine or chemokine levels) 
study, we identified the association of the variant alleles $A A D A T+401 \mathrm{C}>\mathrm{T}$ and APEX1 Asn148Glu with the occurrence of BM. These SNPs were also shown to influence both the innate and adaptive immune responses $[12,13]$. In the present work, we analyzed the association of SNPs in the TNF and $I L-8$ genes and investigated the effects of combining all SNPs, including previously published SNPs $[12,13]$. The low frequency of disease and the poor public health system in Natal (Brazil) did not permit the recruitment of a large group of patients for the study, but our sample size is in accordance with the epidemiological and clinical spectrum of $\mathrm{BM}$ in our region [31, 32].

Systematic differences in ancestry between cases and controls can be found when genetically distinct subgroups demonstrate differing prevalences of target phenotypes [33]. When heterogeneity is equivalent in cases and controls (i.e., the two groups have the same mixture of ethnic/genetic subgroups), stratification does not occur, such as in admixed populations [34]. Although we did not investigate ancestry in our samples, it is known that the Brazilian population has great potential for research due to its admixture, and the various combinations of variants at different loci facilitates the study of gene-gene interactions, which in other homogeneous populations would not be possible. In our specific population, samples were obtained from individuals from northeastern Brazil, which has no specific ethnicity; indeed, this population has the highest degree of admixture in Brazil [35].

Significant differences in the distribution of the individual $T N F-857 \mathrm{C}>\mathrm{T}$ and $I L 8-251 \mathrm{~A}>\mathrm{T}$ variant genotypes between patients and healthy controls were not found (Table 4). However, for the SNP TNF -308G > A, a higher prevalence of the heterozygote in the control group and the homozygote for the wild type allele in the BM group (Table 4) was observed, suggesting a possible protective role against the disease, which must be further investigated. The genotypic frequencies found in our work for SNP TNF -308G > A are similar to those found in other populations [36-38].

Alterations in cytokine and chemokine profiles were observed in the presence of the TNF-308A allele (Fig. 1). Despite the fact that the $P$-value for TNF- $\alpha$ levels had a borderline value, the biological relevance may be considered, as statistical significance was obtained for other cytokines regulated by TNF- $\alpha$. These data corroborate previous work that reported the effect of the SNP TNF $-308 \mathrm{G}>\mathrm{A}$ on TNF gene transcription $[16,17]$. TNF- $\alpha$ is one of the primary pro-inflammatory cytokines that plays a central role in initiating and regulating the inflammatory response, acting as a mediator of resistance to infectious agents, and therefore is important in host defense. TNF- $\alpha$ is involved in the signal transduction pathways that activate cellular NF- $\mathrm{kB}$, which is a transcription factor that regulates the expression of many pro-inflammatory genes [39-41]. Furthermore, TNF- $\alpha$ is indirectly related to the production of immunoglobulin via TGF- $\beta 1$ induction [42].

In several infection models, an inefficient immune response by cytokines and chemokines was associated with a decrease in the clearance of pathogens, the development of invasive disease and high mortality [43-45]. Low levels of IL- $1 \beta$, TNF- $\alpha$ or IL- 6 in nasopharyngeal secretions were observed in children with recurrent episodes of acute otitis media, an important cause of meningitis [46]. These cytokines are important for the activation of chemokines (such as MIP-1 $\alpha /$ CCL3 and MIP-1//CCL4) involved in leukocyte recruitment to the infection site for effective pathogen eradication [47]. However, the severity of meningococcal meningitis is directly correlated with the production of IL- $1 \beta$, TNF- $\alpha$, IL-6 and IL-8 [48, 49].

For complex diseases, the effect of an individual gene is likely to be small and may be modulated by gene-gene or gene-environment interactions [50]. Considering that the pathophysiology of infectious disease involves the interaction of several proteins and pathways, certain genetic combinations suggest a risk factor for the occurrence of severe BM [3, 4]. In this work, certain genotypic combinations were prevalent in BM patients. After analyzing the genotype distributions of the SNP combinations between cases and controls, we found that there were five genotypic combinations that exhibited the highest frequencies in the $\mathrm{BM}$ patient group compared to the control group, particularly the $I L-8 \mathrm{~T} / \_, A P E X 1$ Glu/_, OGG1 Cys/_, PARP1 Ala/_, and AADAT T/_ genotypes (Table 5 ). This indicated that interaction of these five SNPs may result in the occurrence of BM. The combination of the wild type genotype of the TNF gene (GG) with the variant alleles $A A D A T \mathrm{~T} / \_$, APEX1 Glu/_, and $I L 8 \mathrm{~T} /{ }_{-}$also resulted in statistical significance.

In contrast to the other SNPs analyzed, the combination of the two variant alleles of the TNF gene exhibited an interesting additive effect in the control group. Individually, the SNP TNF $-857 \mathrm{C}>\mathrm{T}$ frequency did not suggest an association with $\mathrm{BM}$, as there were no differences between BM and the control group. However, in the control group, the frequency of both the variant $T N F-857 \mathrm{~T}$ and $T N F-308 \mathrm{~A}$ alleles was higher than the BM group, suggesting a possible protective role against infection. However, further studies are needed to confirm this hypothesis.

Analysis of the combined effects of SNPs in comparison to the levels of inflammatory modulators also demonstrated significant associations that may contribute to the increased risk for $\mathrm{BM}$ occurrence. A synergistic effect in cytokine and chemokine expression was 
observed for some genetic combinations. The SNPs APEX1 Asn148Glu, PARP1 Val762Ala and OGG1 Ser326Cys were previously described to be involved in the reduction of DNA repair function [13, 51-53]. In this study, the presence of variant alleles of DNA repair genes was associated with a reduction in the levels of TNF- $\alpha$, MIP- $1 \alpha / C C L 3$, MIP- $1 \beta / C C L 4$ and G-CSF, suggesting a less active inflammatory response in patients who possess this combination.

APE1 and PARP-1 were initially known as DNA repair enzymes but are also important activators and co-factors of the DNA-binding activity of NF- $\mathrm{kB}$ and AP-1 (activator protein1) [54-59], which are master regulators of the inflammatory response $[41,59]$. In addition, these two enzymes may contribute to the regulation of humoral immunity by participating in immunoglobulin class switch recombination $[60,61]$.

In inflammation models such as endotoxic shock, diabetes and contact hypersensitivity, OGG1 gene knockout in mice was shown to be associated with decreased serum cytokine and chemokine levels, which highlights the importance of this enzyme in the inflammatory response [62].

In addition to the role of DNA repair enzymes in the activation of NF- $\mathrm{KB}$ and AP-1, some work has proposed a role for the BER pathway in transcriptional activation, although the mechanisms involved are not well understood. The occurrence of oxidized bases in promoter regions may affect the binding properties of transcriptional factors such as AP-1 [63] or interfere with CpG island methylation, an event that commonly suppresses gene transcription [64]. Recently, Khobta et al. [65] obtained data showing that oxidized bases induce gene silencing in a potential chromatin-mediated mechanism associated with a decrease in histone $\mathrm{H} 4$ acetylation in the promoter region. In addition, the demethylation activity mediated by the LSD1 enzyme produces $\mathrm{H}_{2} \mathrm{O}_{2}$, which locally oxidizes guanine and induces the recruitment of OGG1 and APE1, which are involved in the chromatin remodeling that is necessary for transcriptional activation of the target genes [66]. Based on these studies, polymorphisms in DNA repair enzymes may generate aberrant gene expression, triggering changes in the inflammatory response.

IL-8/CXCL8 is an important mediator that has been implicated in biochemical pathways involved in a wide range of inflammatory diseases [19-21, 67-69]. Activation of CXCL8/IL8 in gastric epithelial cells infected with $H$. pylori is directly dependent on the activation of AP-1, which is regulated by APE1. The silencing of APE1 expression by siRNA causes a reduction in $H$. pylori-induced IL- 8 mRNA and protein, supporting the hypothesis that APE1 is involved in the control of gene expression in bacterial pathogenesis [69]. Although the
SNP IL8 -251A > T was not related to BM occurrence, combination with the variant allele APEX1 148Glu resulted in statistical significance (Table 5). The analysis of immune markers provides evidence that these polymorphisms may exhibit synergism, as a reduction in cytokine and chemokine levels and in cell counts was observed (Fig. 2).

Activation of the KYN pathway was observed during the acute phase of pneumococcal meningitis in infant rats [70]. In a previous study, we also found an association between the kynurenine aminotransferase II gene C401T polymorphism (SNP AADAT $+401 \mathrm{C}>\mathrm{T}$ ) and BM occurrence [12]. Recently, we observed that this polymorphism is associated with an increase in kynurenic acid (KYNA) levels [22], which has anti-inflammatory effects, as it is involved in modulating the immune responses mediated by activation of G protein-coupled receptor 35 (GPR35) [71]. This may explain the lower levels of cyto/chemokines and cell counts observed in patients carrying the $\mathrm{T}$ allele.

The role of chemokines in regulating leukocyte recruitment during infection has also been reported $[45,72,73]$. We observed a significant correlation $(P<0.05)$ between cell counts and IL-1 $\beta$, IL-6, TNF$\alpha$, MIP1- $\alpha$, MIP1- $\beta$ and G-CSF levels in BM patients who had genotypic combinations involving the alleles APEX1 148Glu, IL8 -251T and AADAT +401T (Table 6), suggesting a reduced capacity for leukocyte recruitment in these patients.

During the BM acute phase, an increase occurs in the expression of some cytokines, such as TNF- $\alpha$ and IL-6, which is useful for differential diagnosis with regard to other meningitis types such as aseptic or chronic meningitis [74-76]. As our biological samples intended for the measurement of inflammatory modulators were collected in the acute phase of the disease and the results of the genotype comparisons with reference to cytokine and chemokine levels were not significantly influenced by the time of collection.

\section{Conclusions}

In conclusion, analysis of individual polymorphisms suggested that the TNF -308A allele may play a potential role in protecting against $\mathrm{BM}$. In addition, genetic combinations, primarily involving the TNF -308G, APEX1 148Glu, IL8 -251T and AADAT $+401 \mathrm{~T}$ alleles, were shown to be associated with the inflammatory process in general, leading to decreased expression of cyto/chemokines. This may be related to a reduced ability to eradicate the pathogen and consequent susceptibility to disease. In this paper, we proposed a possible model for gene-gene interactions between important pathways that are activated during BM. However, the low number of patients is a limitation of our work; therefore, collaborative studies conducted in different populations are 
necessary to corroborate our findings. Our data indicate that an extensive evaluation of the variability of these genes may contribute to a better understanding of susceptibility to BM and potentially to other infectious or inflammatory diseases. This knowledge will not only permit clinical interventions but also the implementation of programs for health promotion and disease prevention directed towards susceptible individuals based on their genomic profile, which may lead to decreased morbidity and mortality through risk assessment and improvement of the administration of prophylactic therapies.

\section{Additional file}

Additional file 1: Table S1. Allelic and genotypic frequencies of the SNPs in the studied population. Figure S1. Haplotype map showing the two TNF analyzed polymorphism and a $D^{\prime}$ value of 0.11 , suggesting that the TNF polymorphisms segregate independently (linkage equilibrium). Figure S2. Cytokine and chemokine concentration in relation to the genotype for SNP TNF -308G >A. (A): CSF samples of BM patients. (B): Plasma samples of controls. Figure S3. Cyto/chemokine concentration in CSF samples in relation to the combination of genotypes in BM patients. (A): APEX1 148Glu/_plus/L8-251 T/_ combination. (B): APEX1 148Glu/_ plus OGG1 326Cys/_ and PARP1 I762Ala/_ combination. (C): IL8 T/_ plus APEX1Glu/_ and AADATT/_combination. (D): APEX1 $148 \mathrm{Glu/}$ _ plus AADAT +401 T/_ combination. (E): APEX1 148Glu/_and OGG1 326Cys/_ combination. (F): TNF -308 GG plus/L8 T/_ plus APEX1Glu/_ and AADATT/_ combination. Figure S4. Cyto/chemokine concentration in Plasma samples in relation to the combination of genotypes in controls. (A): APEX1 148Glu/_ plus/L8 -251 T/_combination. (B): APEX1 $148 \mathrm{Glu/}$ _ plus AADAT +401 T/_ combination. (C): IL8T/_ plus APEXIGlu/_ and AADATT/_ combination. It was not possible to compare all combinations in this biological sample due to the small amount of material. Figure S5. Cell count in CSF samples in relation to the combination of genotypes in BM patients: (A): APEX1 148Glu/_ plus OGG1 326Cys/_and PARP1 1762Ala/_ combination. (B): IL8T/_ plus APEX1 Glu/_and AADATT/_ combination. (C): APEX1 148Glu/_andOGG1 326Cys/_ combination. (D): TNF -308 GG plus/L8 T/_ plus APEX1Glu/_ and AADATT/_ combination. (DOCX $773 \mathrm{~kb})$

\begin{abstract}
Abbreviations
AADAT: Aminoadipate aminotransferase; AP-1: Activator protein 1: APE1: Apurinic/apyrimidinic endonuclease 1; BER: Base excision repair; BM: Bacterial meningitis; CNS: Central nervous system; CSF: Cerebrospinal fluid; GMDR: Multifactor dimensionality reduction; GPR35: G protein-coupled receptor 35; HGT: Hospital Giselda Trigueiro; Hib: Haemophilus influenzae type b; KYN: Kynurenine; KYNA: Kynurenic acid; LP: Lumbar puncture;

MMPs: Matrix metalloproteinases; NF-kB: Nuclear transcription factor kappa B; OGG1: 8-oxoguanine DNA glycosylase-1; PARP-1: Poly(ADP-ribose) polymerase-1; PCR-RFLP: Polymerase chain reaction-restriction fragment length polymorphism; PIRA-PCR: Primer-introduced restriction analysispolymerase chain reaction; RNI: Reactive nitrogen intermediates; ROS: Reactive oxygen species; SNP: Single nucleotide polymorphisms; TLRs: Toll-like receptors; TNF-a: Tumor necrosis factor.
\end{abstract}

\section{Competing interests}

The authors declare that they have no competing interests.

\section{Authors' contributions}

Conceived and designed the experiments: LFAL and SLL. Subject recruitment and collection of the samples: FLF, LFA and LGC. Performed and carried out the genotyping experiments: FLF and LFA. Measured chemokines and cytokines: LGC. Analyzed the data and drafted the manuscript: FLF and LFAL. All authors read and approved the final version.

\section{Acknowledgements}

The authors thank the UBS Optimus Foundation and CNPq for the financial support and the team at Hospital Giselda Trigueiro for help with the sample collection. We particularly appreciate the collaboration of Dr. Antonio Gouveia de Oliveira (UFRN) for the statistical analysis. The authors thank Thayse Azevedo da Silva and Fladjule Rejane Soares de Souza for their collaboration in the SNP genotyping at the beginning of the project.

\section{Author details}

'Departamento de Biologia Celular e Genética, Universidade Federal do Rio Grande do Norte, UFRN, Natal, Brazil. ${ }^{2}$ Institute for Infectious Diseases, University of Bern, Friedbuehlstrasse 51, CH-3010 Bern, Switzerland. ${ }^{3}$ Departamento de Biologia Celular e Genética, Centro de Biociências UFRN, Campus Universitário, Lagoa Nova, Natal, RN 59078-970, Brazil.

Received: 19 February 2015 Accepted: 18 August 2015

Published online: 28 August 2015

\section{References}

1. Brouwer MC, Tunkel AR, van de Beek D. Epidemiology, diagnosis, and antimicrobial treatment of acute bacterial meningitis. Clin Microbiol Rev. 2010;23(3):467-92

2. Koedel U, Scheld WM, Pfister HW. Pathogenesis and pathophysiology of pneumococcal meningitis. Lancet Infect Dis. 2002;2(12):721-36.

3. Emonts M, Hazelzet JA, de Groot R, Hermans PW. Host genetic determinants of Neisseria meningitidis infections. Lancet Infect Dis. 2003;3(9):565-77.

4. Sanders MS, van Well GT, Ouburg S, Morré SA, van Furth AM. Genetic variation of innate immune response genes in invasive pneumococcal and meningococcal disease applied to the pathogenesis of meningitis. Genes Immun. 2011;2(5):321-34.

5. Kim KS. Acute bacterial meningitis in infants and children. Lancet Infect Dis 2010:10(1):32-42

6. Mace SE. Central nervous system infections as a cause of an altered mental status? What is the pathogen growing in your central nervous system? Emerg Med Clin North Am. 2010;28(3):535-70.

7. Mogensen TH, Paludan SR, Kilian M, Ostergaard L. Live Streptococcus pneumoniae, Haemophilus influenzae, and Neisseria meningitidis activate the inflammatory response through Toll-like receptors 2, 4, and 9 in speciesspecific patterns. J Leuko Bio. 2006;80(2):267-77.

8. Sjölinder H, Mogensen TH, Kilian M, Jonsson AB, Paludan SR. Important role for Toll-like receptor 9 in host defense against meningococcal sepsis. Infect Immun. 2008;76(11):5421-8.

9. Koedel U, Klein M, Pfister HW. New understandings on the pathophysiology of bacterial meningitis. Curr Opin Infect Dis. 2010;23(3):217-23.

10. Coutinho LG, Grandgirard D, Leib SL, Agnez-Lima LF. Cerebrospinal-fluid cytokine and chemokine profile in patients with pneumococcal and meningococcal meningitis. BMC Infect Dis. 2013;13(1):326.

11. Scheld WM, Koedel U, Nathan B, Pfister HW. Pathophysiology of bacterial meningitis: mechanism(s) of neuronal injury. J Infect Dis. 2002;186 Suppl 2:225-33.

12. de Souza FR, Fontes FL, da Silva TA, Coutinho LG, Leib SL, Agnez-Lima LF. Association of kynurenine aminotransferase II gene C401T polymorphism with imune response in patients with meningitis. BMC Med Genet. 2011;12:51.

13. da Silva TA, Fontes FL, Coutinho LG, de Souza FR, de Melo JT, de Souto JT, et al. SNPs in DNA repair genes associated to meningitis and host immune response. Mutat Res. 2011;713(1-2):39-47.

14. Zádori $D$, Klivényi $P$, Vámos E, Fülöp F, Toldi J, Vécsei L. Kynurenines in chronic neurodegenerative disorders: future therapeutic strategies. J Neural Transm. 2009:116(11):1403-9.

15. Hegde ML, Mantha AK, Hazra TK, Bhakat KK, Mitra S, Szczesny B. Oxidative genome damage and its repair: Implications in aging and neurodegenerative diseases. Mech Ageing Dev. 2012;133(4):157-68.

16. Wilson AG, Symons JA, McDowell TL, McDevitt HO, Duff GW. Effects of a polymorphism in the human tumor necrosis factor alpha promoter on transcriptional activation. Proc Natl Acad Sci U S A. 1997:94(7):3195-9.

17. Lu MC, Yang KL, Tung CH, Huang KY, Yu HC, Liu SQ, et al. Higher LPS stimulated TNF-alpha mRNA levels in peripheral blood mononuclear cells from Chinese ankylosing spondylitis patients with -308G/A polymorphism in 
promoter region of tumor necrosis factor: association with distinct A33/B58/ Cw10 haplotypes. Rheumatol Int. 2008;29(2):189-95.

18. van Heel DA, Udalova IA, De Silva AP, McGovern DP, Kinouchi Y, Hull J, et al. Inflammatory bowel disease is associated with a TNF polymorphism that affects an interaction between the OCT1 and NF(-kappa)B transcription factors. Hum Mol Genet. 2002;11(11):1281-9.

19. Emonts M, Hazes MJ, Houwing-Duistermaat JJ, van der Gaast-de Jongh CE, de Vogel L, Han HK, et al. Polymorphisms in genes controlling inflammation and tissue repair in rheumatoid arthritis: a case control study. BMC Med Genet. 2011:12:36.

20. Spanaus KS, Nadal D, Pfister HW, Seebach J, Widmer U, Frei K, et al. C-X-C and $\mathrm{C}-\mathrm{C}$ chemokines are expressed in the cerebrospinal fluid in bacterial meningitis and mediate chemotactic activity on peripheral blood-derived polymorphonuclear and mononuclear cells in vitro. J Immunol. 1997;158(4):1956-64

21. Hull J, Thomson A, Kwiatkowski D. Association of respiratory syncytial virus bronchiolitis with the interleukin 8 gene region in UK families. Thorax. 2000;55(12):1023-7.

22. Coutinho LG, Christen S, Bellac CL, Fontes F, de Souza F, Grandgirard D, et al. The kynurenine pathway is involved in bacterial meningitis. J Neuroinflammation. 2014;11(1):169.

23. Miller SA, Dykes DD, Polesky HF. A simple salting out procedure for extracting DNA from human nucleated cells. Nucleic Acids Res. 1988;16(3):1215

24. Czerski PM, Rybakowski F, Kapelski P, Rybakowski JK, Dmitrzak-Weglarz M, Leszczyńska-Rodziewicz A, et al. Association of tumor necrosis factor -308G/ A promoter polymorphism with schizophrenia and bipolar affective disorder in a Polish population. Neuropsychobiology. 2008;57(1-2):88-94.

25. Tan EC, Chong SA, Tan CH, Teo YY, Peng K, Mahendran R. Tumor necrosis factoralpha gene promoter polymorphisms in chronic schizophrenia. Biol Psychiatry. 2003;54(11):1205-11.

26. Heinzmann A, Ahlert I, Kurz T, Berner R, Deichmann KA. Association study suggests opposite effects of polymorphisms within IL8 on bronchial asthma and respiratory syncytial virus bronchiolitis. J Allergy Clin Immunol. 2004;114(3):671-6.

27. Sanguinetti CJ, Dias Neto E, Simpson AJ. Rapid silver staining and recovery of PCR products separated on polyacrylamide gels. Biotechniques. 1994;17(5):914-21.

28. Barrett JC, Fry B, Maller J, Daly MJ. Haploview: analysis and visualization of LD and haplotype maps. Bioinformatics. 2005;21(2):263-5.

29. Chen GB, Xu Y, Xu HM, Li MD, Zhu J, Lou XY. Practical and theoretical considerations in study design for detecting gene-gene interactions using MDR and GMDR approaches. PLoS One. 2011;6(2):e16981.

30. Lou XY, Chen GB, Yan L, Ma JZ, Zhu J, Elston RC, et al. A generalized combinatorial approach for detecting gene-by-gene and gene-byenvironment interactions with application to nicotine dependence. Am J Hum Genet. 2007:80(6):1125-37.

31. Azevedo LC, Toscano CM, Bierrenbach AL. Bacterial Meningitis in Brazil: Baseline Epidemiologic Assessment of the Decade Prior to the Introduction of Pneumococcal and Meningococcal Vaccines. PLoS One. 2013;8(6):e64524.

32. Silva WA, Pinheiro AM, Coutinho LG, Marinho LA, Lima LF. Epidemiological profile of acute bacterial meningitis in the state of Rio Grande do Norte, Brazil. Rev Soc Bras Med Trop. 2010;43(4):455-7.

33. Hinds DA, Stokowski RP, Patil N, Konvicka K, Kershenobich D, Cox DR, et al. Matching strategies for genetic association studies in structured populations. Am J Hum Genet. 2004;74(2):317-25.

34. Ardlie KG, Lunetta KL, Seielstad M. Testing for population subdivision and association in four case-control studies. Am J Hum Genet. 2002;71(2):304-11.

35. Pena SD, Di Pietro G, Fuchshuber-Moraes M, Genro JP, Hutz MH, Kehdy Fde $S$, et al. The genomic ancestry of individuals from different geographical regions of Brazil is more uniform than expected. PLoS One. 2011;6(2):e17063.

36. Karplus TM, Jeronimo SM, Chang H, Helms BK, Burns TL, Murray JC, et al. Association between the tumor necrosis factor locus and the clinical outcome of Leishmania chagasi infection. Infect Immun. 2002;70(12):6919-25.

37. Cabrera M, Shaw MA, Sharples C, Williams H, Castes M, Convit J, et al. Polymorphism in tumor necrosis factor genes associated with mucocutaneous leishmaniasis. J Exp Med. 1995;182(5):1259-64.
38. Gaudet MM, Egan KM, Lissowska J, Newcomb PA, Brinton LA, Titus-Ernstoff $L$, et al. Genetic variation in tumor necrosis factor and lymphotoxin-alpha (TNF-LTA) and breast cancer risk. Hum Genet. 2007;121(3-4):483-90.

39. Suryaprasad AG, Prindiville T. The biology of TNF blockade. Autoimmun Rev. 2003;2(6):346-57.

40. Falvo JV, Tsytsykova AV, Goldfeld AE. Transcriptional control of the TNF gene. Curr Dir Autoimmun. 2010;11:27-60.

41. Hayden MS, Ghosh S. NF-KB, the first quarter-century: remarkable progress and outstanding questions. Genes Dev. 2012;26(3):203-34.

42. Tsuji M, Suzuki K, Kitamura H, Maruya M, Kinoshita K, Ivanov II, et al. Requirement for lymphoid tissue-inducer cells in isolated follicle formation and $T$ cell-independent immunoglobulin A generation in the gut. Immunity. 2008;29(2):261-71

43. Lindell DM, Standiford TJ, Mancuso P, Leshen ZJ, Huffnagle GB. Macrophage inflammatory protein 1alpha/CCL3 is required for clearance of an acute Klebsiella pneumoniae pulmonary infection. Infect Immun. 2001;69(10):6364-9.

44. MacLennan IC. Germinal centers. Annu Rev Immunol. 1994;12:117-39.

45. Janoff EN, Rubins JB. Invasive pneumococcal disease in the immunocompromised host. Microb Drug Resist. 1997;3(3):215-32.

46. Lindberg K, Rynnel-Dagöö B, Sundqvist KG. Cytokines in nasopharyngeal secretions; evidence for defective IL-1 beta production in children with recurrent episodes of acute otitis media. Clin Exp Immunol. 1994;97(3):396-402.

47. Zwijnenburg PJ, van der Poll T, Roord JJ, van Furth AM. Chemotactic factors in cerebrospinal fluid during bacterial meningitis. Infect Immun. 2006;74(3):1445-51.

48. Waage A, Halstensen A, Shalaby R, Brandtzaeg P, Kierulf P, Espevik T. Local production of tumor necrosis factor a, interleukin 1, and interleukin 6 in meningococcal meningitis. Relation to the inflammatory response. J Exp Med. 1989;70(6):1859-67.

49. Waage A, Halstensen A, Espevik T. Association between tumour necrosis factor in serum and fatal outcome in patients with meningococcal disease. Lancet. 1987;1(8529):355-7.

50. Stranger BE, Stahl EA, Raj T. Progress and promise of genome-wide association studies for human complex trait genetics. Genetics. 2011;187(2):367-83.

51. Wang XG, Wang ZQ, Tong WM, Shen Y. PARP1 Val762Ala polymorphism reduces enzymatic activity. J Biol Chem. 2007;354(1):122-6.

52. Xanthoudakis S, Miao GG, Curran T. The redox and DNA-repair activities of Ref-1 are encoded by nonoverlapping domains. Proc Natl Acad Sci U S A. 1994;91(1):23-7.

53. Hill JW, Evans MK. Dimerization and opposite base-dependent catalytic impairment of polymorphic S326C OGG1 glycosylase. Nucleic Acids Res. 2006;34(5):1620-32.

54. Xanthoudakis S, Miao G, Wang F, Pan YC, Curran T. Redox activation of Fos- Jun DNA binding activity is mediated by a DNA repair enzyme. EMBO J. 1992;11(9):3323-35.

55. Mitomo K, Nakayama K, Fujimoto K, Sun X, Seki S, Yamamoto K. Two different cellular redox systems regulate the DNA-binding activity of the p50 subunit of NFkappa B in vitro. Gene. 1994;145(2):197-203.

56. Nishi T, Shimizu N, Hiramoto M, Sato I, Yamaguchi Y, Hasegawa M, et al. Spatial redox regulation of a critical cysteine residue of NF-kappa B in vivo. J Biol Chem. 2002;277(46):44548-56.

57. Aguilar-Quesada R, Muñoz-Gámez JA, Martín-Oliva D, Peralta-Leal A, QuilesPérez R, Rodríguez-Vargas JM, et al. Modulation of transcription by PARP-1: consequences in carcinogenesis and inflammation. Curr Med Chem. 2007;14(11):1179-87.

58. Hassa PO, Hottiger MO. The functional role of poly(ADP-ribose)polymerase 1 as novel coactivator of NF-kappaB in inflammatory disorders. Cell Mol Life Sci. 2002;59(9):1534-53.

59. Schonthaler HB, Guinea-Viniegra J, Wagner EF. Targeting inflammation by modulating the Jun/AP-1 pathway. Ann Rheum Dis. 2011;70 Suppl 1:1109-12.

60. Ambrose HE, Willimott S, Beswick RW, Dantzer F, de Murcia JM, Yelamos J, et al. Poly(ADP-ribose) polymerase-1 (Parp-1)-deficient mice demonstrate abnormal antibody responses. Immunology. 2009;127(2):178-86.

61. Guikema JE, Linehan EK, Tsuchimoto D, Nakabeppu Y, Strauss PR, Stavnezer J, et al. APE1- and APE2-dependent DNA breaks in immunoglobulin class switch recombination. J Exp Med. 2007;204(12):3017-26.

62. Mabley JG, Pacher P, Deb A, Wallace R, Elder RH, Szabó C. Potential role for 8- oxoguanine DNA glycosylase in regulating inflammation. FASEB J. 2005;19(2):290-2. 
63. Ghosh R, Mitchell DL. Effect of oxidative DNA damage in promoter elements on transcription factor binding. Nucleic Acids Res. 1999;27(15):3213-8.

64. Valinluck V, Tsai HH, Rogstad DK, Burdzy A, Bird A, Sowers LC. Oxidative damage to methyl-CpG sequences inhibits the binding of the methyl-CpG binding domain (MBD) of methyl-CpG binding protein 2 (MeCP2). Nucleic Acids Res. 2004;32(14):4100-8.

65. Khobta A, Anderhub S, Kitsera N, Epe B. Gene silencing induced by oxidative DNA base damage: association with local decrease of histone $\mathrm{H} 4$ acetylation in the promoter region. Nucleic Acids Res. 2010;38(13):4285-95.

66. Amente S, Bertoni A, Morano A, Lania L, Avvedimento EV, Majello B. LSD1mediated demethylation of histone $\mathrm{H} 3$ lysine 4 triggers Myc-induced transcription. Oncogene. 2010;29(25):3691-702

67. Goverdhan SV, Ennis S, Hannan SR, Madhusudhana KC, Cree AJ, Luff AJ, et al. Interleukin-8 promoter polymorphism -251A/T is a risk factor for agerelated macular degeneration. Br J Ophthalmol. 2008;92(4):537-40.

68. Tsirpanlis G. Cellular senescence and inflammation: a noteworthy link. Blood Purif. 2009;28(1):12-4

69. O'Hara AM, Bhattacharyya A, Bai J, Mifflin RC, Ernst PB, Mitra S, et al. Tumor necrosis factor (TNF)-alpha-induced IL-8 expression in gastric epithelial cells: role of reactive oxygen species and AP endonuclease-1/redox factor (Ref)-1. Cytokine. 2009:46(3):359-69.

70. Bellac CL, Coimbra RS, Christen S, Leib SL. Inhibition of the kynurenine- NAD + pathway leads to energy failure and exacerbates apoptosis in pneumococcal meningitis. J Neuropathol Exp Neurol. 2010;69(11):1096-104.

71. Wang J, Simonavicius N, Wu X, Swaminath G, Reagan J, Tian H, et al. Kynurenic acid as a ligand for orphan $\mathrm{G}$ protein-coupled receptor GPR35. J Biol Chem. 2006:281(31):22021-8.

72. Møller AS, Bjerre A, Brusletto B, Joø GB, Brandtzaeg P, Kierulf P. Chemokine patterns in meningococcal disease. J Infect Dis. 2005;191(5):768-75.

73. Lapinet JA, Scapini P, Calzetti F, Pérez O, Cassatella MA. Gene expression and production of tumor necrosis factor alpha, interleukin-1beta (IL-1 beta), IL-8, macrophage inflammatory protein 1alpha (MIP-1alpha), MIP-1beta, and gamma interferon-inducible protein 10 by human neutrophils stimulated with group B meningococcal outer membrane vesicles. Infect Immun. 2000;68(12):6917-23.

74. Torre D, Zeroli C, Ferraro G, Speranza F, Tambini R, Martegani R, et al. Cerebrospinal fluid levels of IL-6 in patients with acute infections of the central nervous system. Scandinavian J Infect Dis. 1992;24(6):787-91.

75. Mukai AO, Krebs VL, Bertoli CJ, Okay TS. TNF-alpha and IL-6 in the diagnosis of bacterial and aseptic meningitis in children. Pediatr Neurol. 2006;34(1):25-9.

76. Akalin H, Akdiş AC, Mistik R, Helvaci S, Kiliçturgay K. Cerebrospinal fluid interleukin-1 beta/interleukin-1 receptor antagonist balance and tumor necrosis factoralpha concentrations in tuberculous, viral and acute bacterial meningitis. Scand J Infect Dis. 1994;26(6):667-74.

\section{Submit your next manuscript to BioMed Central and take full advantage of:}

- Convenient online submission

- Thorough peer review

- No space constraints or color figure charges

- Immediate publication on acceptance

- Inclusion in PubMed, CAS, Scopus and Google Scholar

- Research which is freely available for redistribution 